\title{
Performance Analysis of Urban Cleaning Devices Using Human-Machine Interaction Method
}

\author{
María Alonso-García ${ }^{1, *(\mathbb{D}}$, Ana García-Sánchez ${ }^{1}$, Paula Jaén-Moreno ${ }^{1}$ and Manuel Fernández-Rubio ${ }^{2}$ \\ 1 Mechanical Engineering and Industrial Design Department, University of Cádiz, Av. de la Universidad 10, \\ Puerto Real, 11519 Cádiz, Spain; a.garciasanchez@alum.uca.es (A.G.-S.); pau.jaenmore@alum.uca.es (P.J.-M.) \\ 2 Feniks Cleaning and Safety S.L., Calle Fridex Uno 3, Alcalá de Guadaíra, 41500 Sevilla, Spain; \\ mfernandez@feniks.es \\ * Correspondence: maria.alonso@uca.es
}

check for

updates

Citation: Alonso-García, M.;

García-Sánchez, A.; Jaén-Moreno, P.; Fernández-Rubio, M. Performance

Analysis of Urban Cleaning Devices Using Human-Machine Interaction Method. Sustainability 2021, 13, 5846. https://doi.org/10.3390/su13115846

Academic Editors: Nicoleta

Luminita Carutasu and

Anca Draghici

Received: 7 March 2021

Accepted: 17 May 2021

Published: 22 May 2021

Publisher's Note: MDPI stays neutral with regard to jurisdictional claims in published maps and institutional affiliations.

Copyright: (c) 2021 by the authors. Licensee MDPI, Basel, Switzerland. This article is an open access article distributed under the terms and conditions of the Creative Commons Attribution (CC BY) license (https:/ / creativecommons.org/licenses/by/ $4.0 /)$.

\begin{abstract}
Presently, several jobs require the collaboration of humans and machines to perform different services and tasks. The ease and intuitiveness of the worker when using each machine will not only improve the worker's experience but also improve the company's productivity and the satisfaction that all users have. Specifically, electromechanical devices used to provide cleaning services require complex interactions. These interactions determine the usability and performance of devices. Therefore, devices must have appropriate ergonomic arrangements for human-machine interactions. Otherwise, the desired performance cannot be achieved. This study analyzes the performance of an urban cleaning device (pressure washer on a power take-off van) using humanmachine interaction method. The method measures visceral and behavioral levels (set by Norman) and service times. Using these measurements, the usability of the pressure washer is determined according to different factors that facilitate the operator's well-being in the working environment. A pressure washer from Feniks Cleaning and Safety, Limited Company, has been studied. Sixteen errors related to ergonomics, usability and safety were identified in this machine, which operates in more than 40 locations in Spain. Therefore, this study provides valuable information on the usability and performance of pressure washers, as well as possibilities for improvement.
\end{abstract}

Keywords: experience design; product evaluation; human-machine interaction; service industries; work productivity; human performance; human factors; industrial design

\section{Introduction}

Today, innovation is a key factor in increasing a company's competitiveness in today's globalized market. Industrial design and product development can contribute to this innovation by creating aesthetic, functional and marketable products [1]. With this discipline, it is possible to establish the multifaceted qualities of objects, processes, services and systems throughout their life cycle [2].

Therefore, the range of products on the market is becoming wider and wider, irrespective of their nature, allowing the user to have a greater demand for products. However, despite this increase in supply, the user has less reaction time to select a model [3]. For this reason, new product development (NPD) can be an attractive and necessary strategic tool for companies. NPD is able to satisfy, in general, the needs and desires of users and costumers, including ergonomic improvements, which increase the usability of each product [4-6] and ensures a good user experience [7].

In the specific case of the work environment, NPD is also an important factor for improving the well-being of workers. Recent research establishes that technological innovation and current ways of working are causing various health problems for workers [8]. These problems can lead to occupational diseases, which are considered one of the major public health problems worldwide. The diseases arise from various hazards that threaten 
the well-being of workers, such as biological, chemical, physical, ergonomic and psychological hazards [9].

Some types of risks do not affect all workers. Chemical or biological hazards affect, for example, medical service personnel [9]. Meanwhile, physical hazards affect jobs requiring significant physical activity, such as those related to the construction sector [10]. Although these risks do not affect all workers, ergonomic and psychological hazards can affect any type of job. These problems affect workers who perform more sedentary tasks, such as office workers [11] or teachers [12]. However, it also affects workers who perform tasks requiring moderate or high physical activity. Among them are urban street cleaners, who use the devices studied in this research. In this regard, there is a large body of research that attempts to analyze and prevent such risks. In general, these investigations are developed according to the environment in which the worker performs the task and accordingly the tools used. However, they are mostly related to jobs requiring high or low physical activity and are not related to jobs with moderate physical activity.

In addition, current research concerns ergonomic issues related to the posture of the worker [10-12], the layout of potential hazards in the working environment [9], the visual quality of the digital elements required during working time [11], the lighting of the workstation [13], etc.

These research studies, and in particular those related to physical risks, focus on three approaches to identify physical risk factors that can cause musculoskeletal disorders. The first involves the assessment of self-reports by workers, who are asked to estimate the levels of risk associated with their work. The second is to observe and analyze the work in realtime, or through recordings, to classify risk factors. The third directly measures the worker's posture in each task [14]. Assessments based on the second approach (observation) are the most commonly used. They allow rapid assessment of upper extremities (RULA) [15], the whole body (REBA) [16] and office strain (ROSA) [17]. Its advantages lie in the possibility to study levels of cost, capacity, versatility, generality and precision according to the needs of specialists and with limited time and resources [18]. Observation can be done in real-time or by direct recording by the user. Some studies also propose stereoscopy as a tool to improve workplace ergonomics. Gašo et al. describe a procedure for creating a stereoscopic register that improves ergonomics and optimizes the company's profit [19]. Marogel et al. develop an analysis of the postural risk in manual poplar planting operations based on the records of different subjects [20]. This study suggests that the work methodology of these workers is focused on developing an effective plantation, which has led to poor working postures, and suggests designing these operations for the worker and not the business. Other more advanced research proposes the use of Industry 4.0 and new technologies for the development of ergonomic simulations. Some authors recommend the use of 3D modeling and simulation software, as in the case of [21], which proposes 2DSSPP and AutoCAD for evaluation in the context of workstations and prevention of physical risks. Innovative workplace assessment solutions based on augmented reality are also presented. These combine "manual" observation with 3D simulation, allowing interactions between the real and virtual world [22]. Matos et al. use the ROSA method to assess a specific job. They subdivide the risk factors into several subsections (chair, monitor and telephone, mouse and keyboard) analyzing the risk factors for each component. The results obtained show that the analyzed tasks and workstations represent risk situations and that further investigations and modifications of the workstation may be necessary [23].

Although, as mentioned above, there are several research studies and methodologies to measure the ergonomic quality of each workstation, most of them do not address tasks involving human-machine interaction. In addition, the studies mentioned above evaluate the workplace in terms of user ergonomics or in terms of workplace cost-effectiveness. However, as a rule, they do not are related to both questions.

In this regard, it is important to highlight that human-machine interaction is of vital importance. These interactions will not only affect the well-being of the worker, but also the service time and profitability of the company. Human-machine interactions that involve 
worker welfare will also ensure efficient and optimal service. Although there are no relevant studies on these cases, several authors focus their research on the physical interactions of users with everyday products to study not only the ergonomics, usability and intuitiveness of products, but also the emotions they arouse in users [24-26]. This can serve as a basis for the study of human-machine interaction in the work environment, where products are required to perform different tasks or services. Paying attention to the ergonomic aspects of the different products and processes used in the working environment is even more important to ensure maximum worker safety.

On the other hand, although most innovative products appear potentially successful, they often manifest some failures and errors during their market introduction. This is due to the lack of user consultation during the initial and final phases of the product design process [3]. The problem is not only with everyday products but also with products, tools and machines used in the execution of work tasks, in which case the working user has less power to make demands on his or her superiors. It is therefore particularly important to use tools that test and measure the success of these devices or machines, with an emphasis on usability, ergonomics and service time, as in other research on everyday products [27,28].

To this end, there are a number of specific methodologies and tools for the design of products according to the user's needs. Although these methodologies are usually used for generic products, they can be applied to the tools and utensils needed to perform a specific profession or task. Two of them are User-Centered Design or UCD and Emotional Design established by Norman [29-31].

UCD attempts to identify the needs and desires of users in the product through their own participation in the product design process [32,33]. This methodology establishes the design requirements by placing the user at the center of the process. It is supported by numerous user consultation tools, such as interviews, surveys, observation, focus groups, Delfi panels, ethnographic groups, etc. [34-36], which guarantees good product acceptance and user experience [37]. Emotional design, however, argues that the target user himself is able to represent his needs in the product better than any other user [30] and that what a user is really looking for in a product is to establish a lasting relationship with it. To apply this theory, Norman establishes three levels of analysis: visceral, behavioral and reflexive. These levels allow the study of the user's first impression of the product, the user's perception during the product use and the user's interest in maintaining the product over time $[30,31]$. Both methodologies advocate user consultation from the early stages of the design process to the final validation of prototypes.

In the specific case of vehicles used for the development of public or private services, these are vehicles whose interiors have to be adapted by specialized companies. This means that, although the interior of each model could be fully customized to the needs of the service and the customers, this would be too costly for both the provider and the customer. Consequently, there is a tendency to develop levels of customization limited to the type of service offered, often resulting in the need for the user to adapt to the machine, and dissatisfaction with the final product.

The aim of this research is to establish a starting point for the correct adaptation, through the design process, of vehicles intended for the development of public or private services to workers. This work seeks to detect errors in the human-machine interaction that allow the interior of the vehicle to be adapted to the worker and the service to be performed and not the other way around.

For this purpose, a case study is established to analyze and improve an urban cleaning vehicle in order to reduce service times, increase worker safety and improve the usability of the machine by placing the worker at the center of the process, as UCD does. The vehicle analyzed is a van-mounted power take-off pressure washer marketed by Feniks to the main street cleaning companies in Spain.

The paper is structured as follows. Section 2 presents the proposed methodology, Section 3 describes the experimental results and Section 4 concludes and summarizes the main developments of this research. 


\section{Materials and Methods}

In order to ensure an optimal street cleaning service, a machine interaction analysis of the selected vehicle is presented. This analysis is carried out as part of the process of new hydro-cleaners solutions. The development of the project is based on the collaboration between the University of Cádiz and Feniks Cleaning and Safety, Limited Company. In this way, different members of both entities coordinate the company's expertise with the university's research capabilities.

The case study presented here aims to improve the street cleaning service by optimizing the machine and thus the worker's interaction with it. This approach aims to benefit both the well-being of the workers and the productivity of the company. Thus, the analysis has been carried out on the basis of three variables: safety $(\mathrm{S})$, service time $(\mathrm{T})$ and usability (U). These variables are represented in Figure 1, as well as the rest of the process.

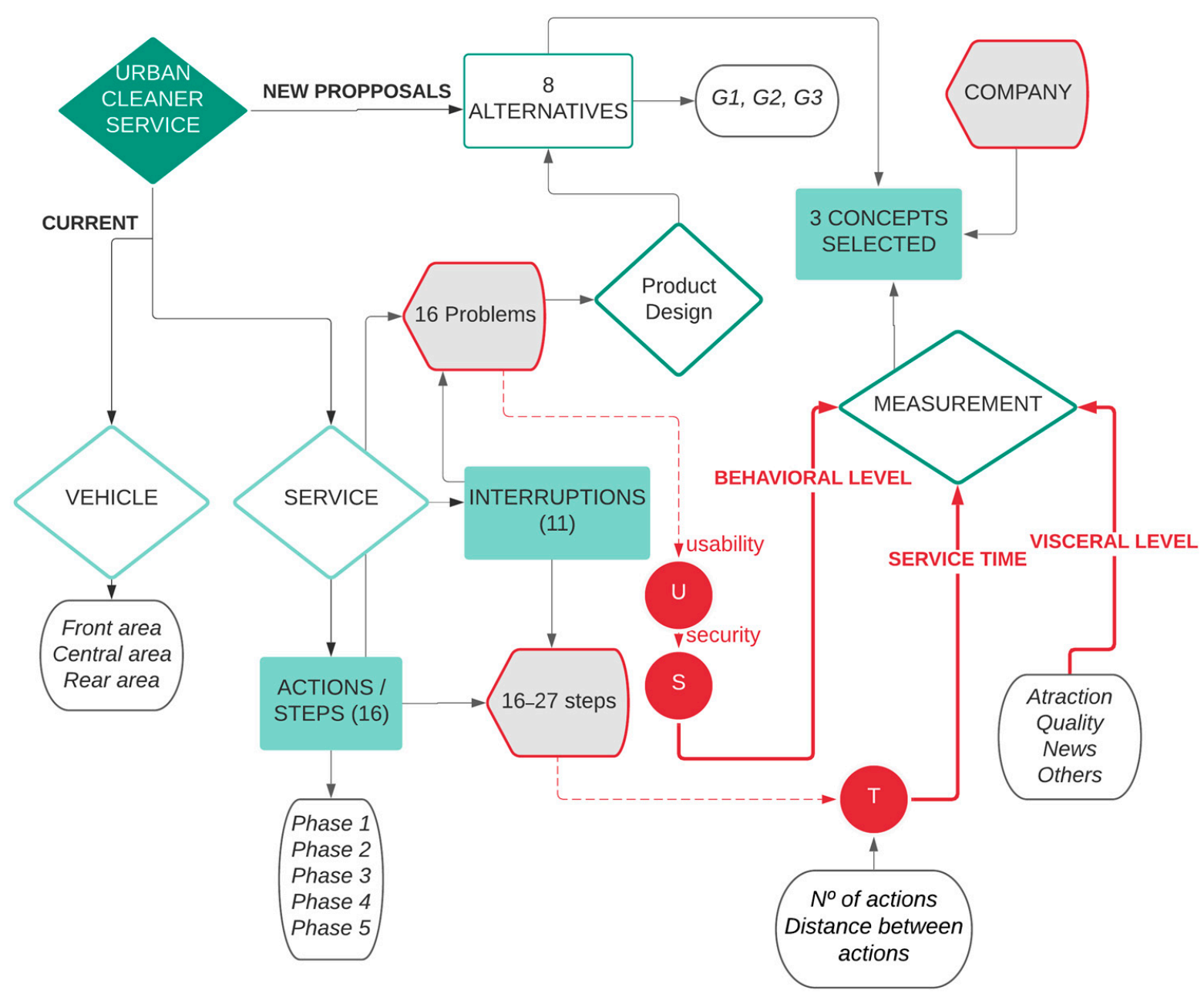

Figure 1. Analysis process.

As shown in this figure, the study begins with the preliminary analysis of the street cleaner service. In order to carry out this analysis, the current vehicle and service have been described. For this purpose, the vehicle and its components are divided into three areas and the service into 5 phases. In this way, the actions to be carried out in each phase can be positioned in each area.

On the other hand, the different disruptions that may occur during the service are also analyzed. By analyzing these disruptions, it is possible to consider the total number of tasks or actions needed as a starting point to improve the service time (T). Furthermore, with this analysis, the current usability (U) and security (S) problems are also defined. 
Based on these problems and actions, different alternatives have been designed with some improvements to the vehicle and the service. With these alternatives, grouped into 3 different groups according to their approach, the company carries out an initial screening based on economic viability criteria. The selected proposals are evaluated according to the sizing of the three proposed variables: $\mathrm{U}, \mathrm{T}$ and $\mathrm{S}$.

The following sections present the details of this research as follows: (1) description of the current vehicle and service, (2) design and selection of improvement proposals for analysis and (3) procedure used for the analysis and comparison of these proposals with the current pressure washer.

\subsection{Vehicle and Service Analyzed}

\subsubsection{Current Vehicle Description}

The selected vehicle has three clearly differentiated zones. Figure 2a shows the first one, which corresponds to the driver's zone. This area contains the power take-off and the engine pump. The next zone contains the tank, the base plate, different plastic containers and the collection tray. It also contains the boiler, which protrudes from the top of the vehicle (Figure 2b). Finally, Figure $2 c$ represents the area where most of the interactions between the worker and the vehicle take place. It contains several tools located on different shelves, the high-pressure water gun and the hose reel. This area is equipped with a control panel board to display pressure and water levels.

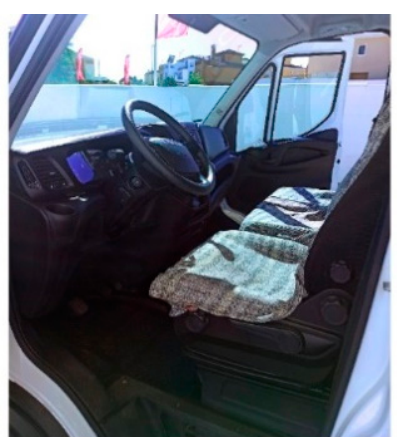

(a)

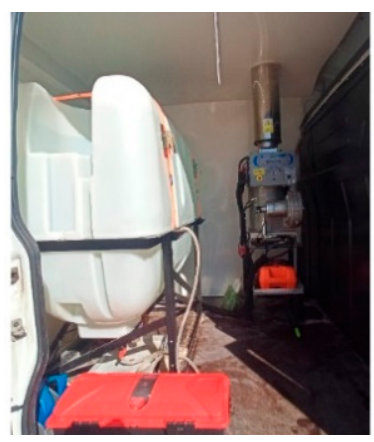

(b)

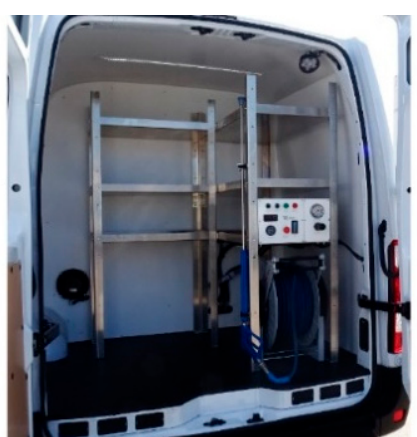

(c)

Figure 2. Different zones of the analyzed vehicle. Front (a), central (b) and rear (c).

\subsubsection{Current Service Description and Human-Machine Interaction}

During the performance of each service, workers must complete several vehicle interaction activities. These actions are classified according to the vehicle's zone (front, central and rear), and the phase of the operator's routine in which each action is performed. In this sense, the operator's routine divides the service into 5 phases. These phases correspond to preliminary checks (Phase 1), driving the vehicle to the place where the cleaning is to be carried out (Phase 2), starting the vehicle (Phase 3), cleaning the container or the public road (Phase 4) and stopping the vehicle (Phase 5). In addition to these phases, it is important to take into account several interruptions that can delay service.

Table 1 lists the actions required (Figure 3) for each phase (columns 1-5), as well as the possible interruptions (column 6). Based on these data, between 16 and 27 actions are required for each current service. This unit has been taken as a starting point for service improvement to reduce service duration. 
Table 1. Operator's routine.

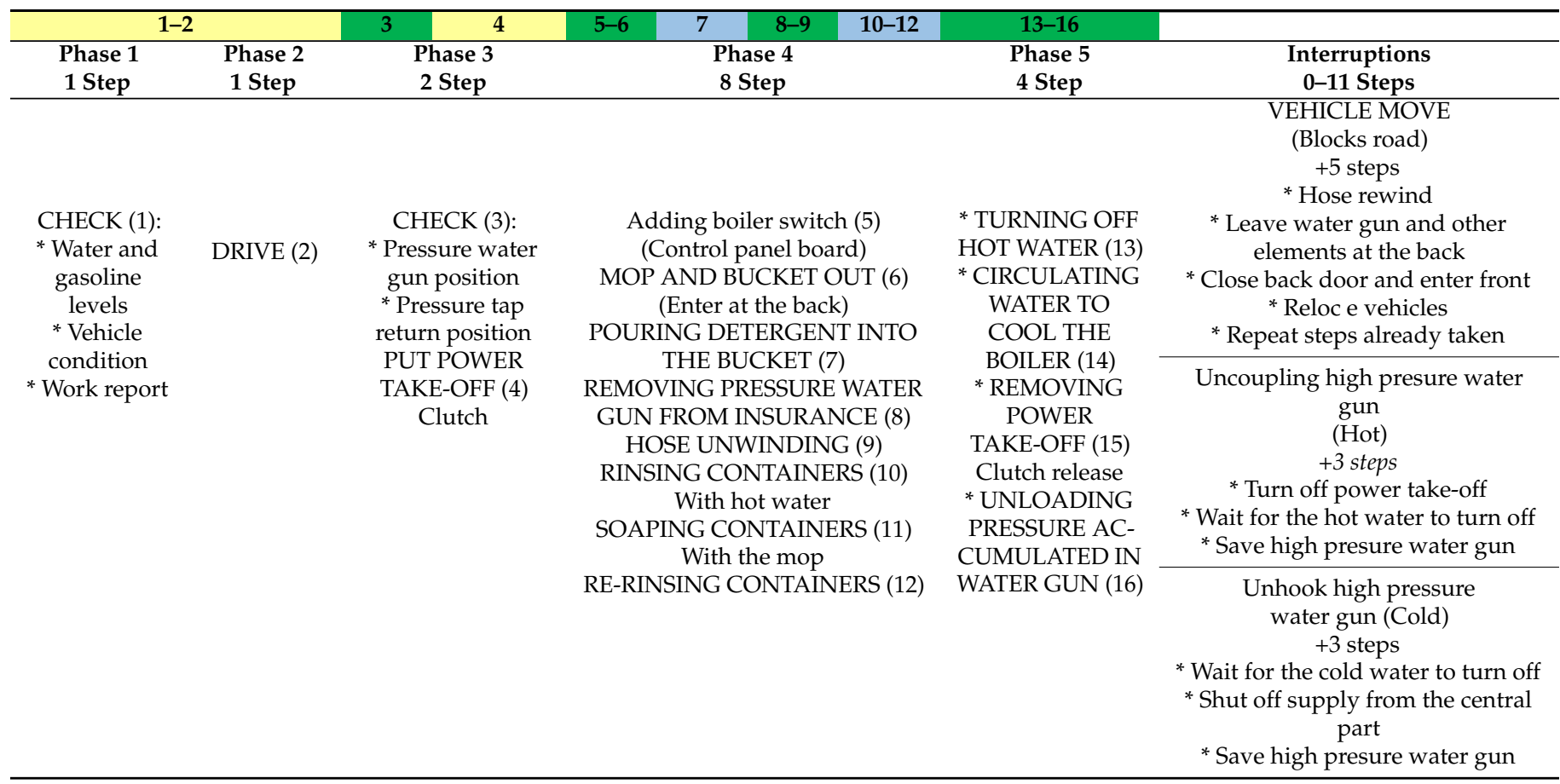
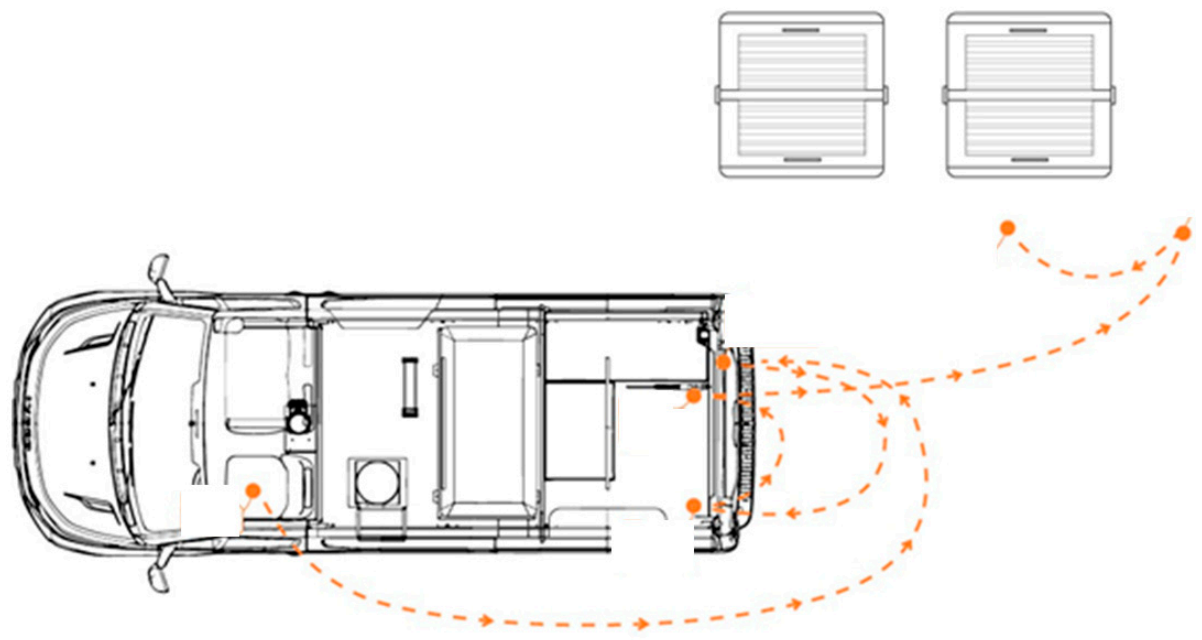

Figure 3. Operator's routine.

The 16 actions refer to the area of the vehicle in which they are to be performed. Those to be performed in the front zone are indicated in yellow and those to be carried out in the rear zone in green. No action is required in the central zone of the vehicle. On the other hand, actions indicated in blue must be performed outside the vehicle on the public road.

\subsection{Design and Selection of Alternative Concepts}

Based on the problems and actions detected in the analysis of the current service, eight proposals for a new urban cleaning vehicle concept are made. These concepts have been developed in three groups according to the requirement studied above.

The first group (G1) comprises four proposals for improvement of individual elements. However, groups 2 and 3 include four global proposals (G2-G3), which also involve different individual elements.

The modifications presented in the first group (M1, M2, M3 and M4) do not involve any changes to the arrangement of the existing elements. These proposals individually 
improve the "control panel board" (M1), the "detergent container" (M2), the "hose reel" (M3) and the "high-pressure water gun" (M4).

The M5, M6, M7 and M8 proposals present some changes in the layout of the different elements. The common idea is to make more use of the central part of the vehicle (currently in disuse). Although this area is the most accessible, it is currently the rear one where most of the actions take place.

In particular, the proposals of the second group (M5 and M6) propose an interchange in the arrangement of the individual elements located in the rear and central zones. The M5 concept proposes the alteration of the central and rear parts of the vehicle by means of rails. However, the M6 concept proposes the redistribution of the space in the central part and the lowering of the control panel board, leaving more space for the worker inside. The M7 and M8 (G3) concepts propose the use of the central zone for the development of the most common actions.

The M7 concept seeks to expand the space in the rear area of the vehicle. The M8 concept facilitates the worker's interaction with this same area without the need to access it. The different concepts are listed below, indicating the zone(s) that would be affected by their modifications (Table 2).

Table 2. Proposals analyzed.

\begin{tabular}{|c|c|c|c|c|c|c|c|}
\hline & & \multirow{2}{*}{ Code } & \multirow{2}{*}{ Alternatives } & \multicolumn{3}{|c|}{ Affected Area(s) } & \multirow{2}{*}{ Description } \\
\hline & & & & Front & Central & Back & \\
\hline \multirow{4}{*}{$\begin{array}{l}\text { No change in } \\
\text { distribution }\end{array}$} & \multirow{4}{*}{$\begin{array}{l}\text { Individual } \\
\text { modifications } \\
\text { (G1) }\end{array}$} & M1 & Control panel board & & & $x$ & \\
\hline & & M2 & Detergent container & & & $x$ & \\
\hline & & M3 & Hose reel & & & $x$ & \\
\hline & & M4 & High pressure water gun & & & $x$ & \\
\hline \multirow{4}{*}{$\begin{array}{l}\text { With change in } \\
\text { distribution }\end{array}$} & \multirow{2}{*}{$\begin{array}{l}\text { Exchange of } \\
\text { central and back } \\
\text { area (G2) }\end{array}$} & M5 & Global alternative 1 & & $x$ & $x$ & Proposed rails \\
\hline & & M6 & Global alternative 2 & & $X$ & $x$ & $\begin{array}{l}\text { Proposal with hinged } \\
\text { control panel }\end{array}$ \\
\hline & \multirow{2}{*}{$\begin{array}{l}\text { Improved back } \\
\text { area organization } \\
\text { (G3) }\end{array}$} & M7 & Global alternative 3 & & & $x$ & $\begin{array}{l}\text { Proposal to facilitate } \\
\text { entry to the van }\end{array}$ \\
\hline & & M8 & Global alternative 4 & & & $x$ & $\begin{array}{l}\text { Proposal to prevent the } \\
\text { operator from entering } \\
\text { the van }\end{array}$ \\
\hline
\end{tabular}

From these 8 proposals, the company selects 3 models, one from each group: M1, M5 and M7. The selection was made on the basis of the positive aspects they present in relation to the problems indicated above, but also on the basis of manufacturability and economic requirements (Table 3 ).

Table 3. Selection of proposals.

\begin{tabular}{|c|c|c|c|c|c|c|c|c|}
\hline & M1 & M2 & M3 & M4 & M5 & M6 & M7 & M8 \\
\hline \multicolumn{9}{|l|}{ Simple service control } \\
\hline \multicolumn{9}{|l|}{ Easy use of detergent } \\
\hline \multicolumn{9}{|c|}{ Facilitate hose collection } \\
\hline \multicolumn{9}{|c|}{ Easy proper disposal high-pressure water gun } \\
\hline \multicolumn{9}{|c|}{ Use of central area } \\
\hline \multicolumn{9}{|l|}{ Providing access to tools } \\
\hline Problem-solving req. & 1 & 1 & 1 & 1 & 2 & 2 & 3 & 2 \\
\hline Manufacturability req. & + & ++ & ++ & +++ & ++ & +++ & ++ & +++ \\
\hline Economic req. & $€$ & $€$ & $€$ & $€ € €$ & $€ €$ & $€ € €$ & $€$ & $€ € €$ \\
\hline
\end{tabular}

According to this table, it can be seen that the M7 concept solves 3 problems while the rest of the proposals only solve 1 or 2 . This concept is inexpensive and of medium 
manufacturing difficulty. The M6 and M8 concepts are more expensive and more difficult to manufacture than the M5, which has the same positive aspects as M6 and M8, in a simpler and cheaper way. Among the remaining proposals, which only have one positive aspect, the M1 concept is the simplest and most cost-effective. This selection also makes it possible to combine 2 or 3 concepts in the same design. The concepts M1, M5 and M7 present all aspects together.

\subsection{Case Study and Analysis Methodology: Description and Process}

The development of the case study and the analysis of the results are based on a previous phase of observation of the current service and human-machine interaction. Therefore, it was necessary to establish the different errors detected in this interaction on the basis of an analysis phase. For this purpose, three experienced workers from two urban cleaning companies were consulted in a first phase. The observation of these workers interacting with the vehicle and the different elements was fundamental to be able to detect errors and deficiencies in the current service (Figure 4). The participating companies were CESPA, Public Company, located in Coria del Río (Seville-Spain) and VERTRESA, Public Company, located in Chiclana de la Frontera (Cádiz-Spain).

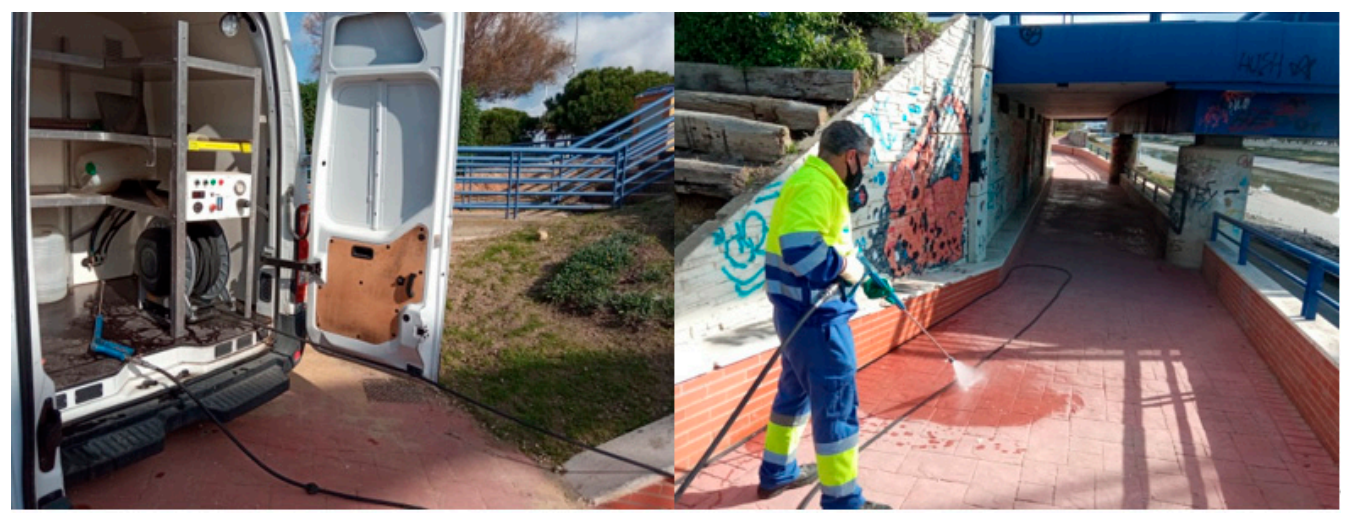

Figure 4. Early stage of process. Worker observation in VETRESA, Public Company, Chiclana (Cádiz-Spain).

The problems detected in this phase have been assessed in the three proposals mentioned above. For this purpose, in addition to the three workers consulted in the early stage, 73 inexperienced users were consulted throughout the process. These users were involved in more advanced phases to check which problems had been solved by the different proposals and which had not. All participating users were between 18 and 65 years old, the legal age for working and driving (Figure 5).

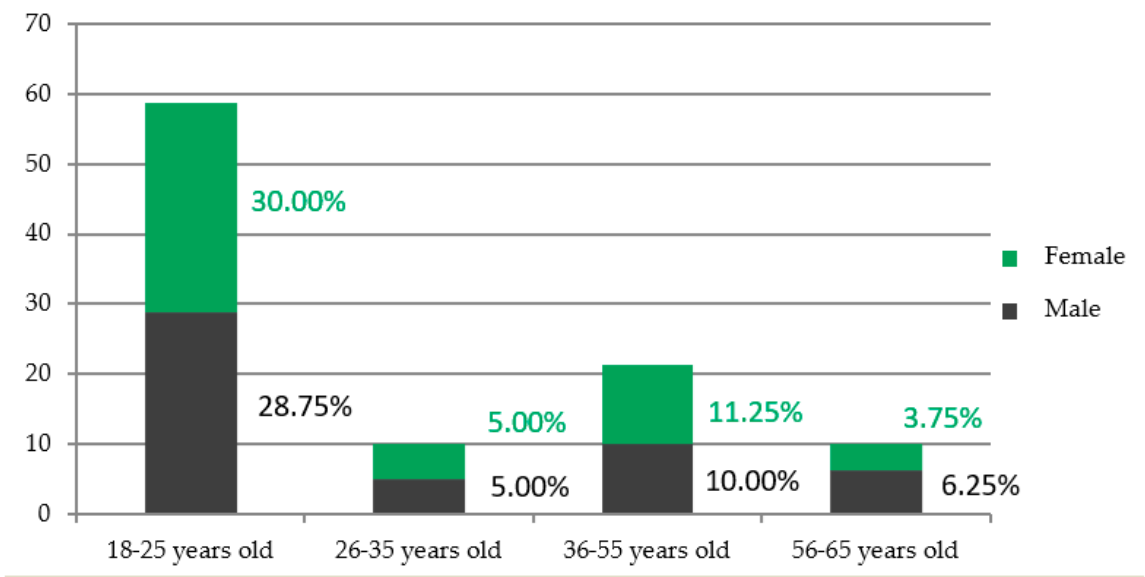

Figure 5. Distribution of users consulted. 
Using characteristic tools of UCD, such as interviews with experienced workers and their observation during their the working day, the aim is to analyze the current human-machine experience during the early stages. The problems identified fall into three established variables: S, T and U. In the case of "Safety", pedestrians and urban furniture were taken into account. "Service Time" and "Usability" only relate to the worker.

Based on surveys and focus groups aimed at users with no experience in driving this type of vehicle, the perceived intuitiveness of the different proposals is analyzed. These consultations have allowed measurements to be made in different areas based on the study of different parameters. These parameters are included in the "time of use" dimension mentioned above and also in the visceral and behavioral levels established by Norman [14]. This allows the immediate emotional and behavioral response of a user to a product to be measured (Table 4).

Table 4. Parameters evaluated.

\begin{tabular}{|c|c|c|c|c|c|c|}
\hline Dimension & & Parameter & Method & Scale & Technique/Tool & Observations \\
\hline \multirow[b]{2}{*}{ Service time } & \multirow[b]{2}{*}{ Actions } & $\mathrm{N}^{\circ}$ of actions & $\mathrm{O}$ & - & & - \\
\hline & & Distance between actions & $\mathrm{O}$ & $1-3$ & $\begin{array}{l}\text { Low (1), Medium (2) or } \\
\text { High (3) }\end{array}$ & - \\
\hline \multirow{4}{*}{ Behavioral level } & \multirow{3}{*}{ Usability } & Intuitiveness & $\begin{array}{l}\mathrm{C} \\
\mathrm{C}\end{array}$ & $\begin{array}{l}1-6 \\
1-6\end{array}$ & $\begin{array}{l}\text { Semantic differential } \\
\text { Semantic differential }\end{array}$ & $\begin{array}{c}\text { Easy/Hard to use } \\
\text { Simple/Technological }\end{array}$ \\
\hline & & Cleaning and maintenance & C & $1-6$ & Associated words & Dirty/Clean \\
\hline & & Others & C & - & Associated words & Repetition \\
\hline & & Security & A & - & - & - \\
\hline Visceral level & & $\begin{array}{l}\text { Attraction } \\
\text { Quality } \\
\text { New } \\
\text { Others }\end{array}$ & $\begin{array}{l}\mathrm{C} \\
\mathrm{C} \\
\mathrm{C} \\
\mathrm{C}\end{array}$ & $\begin{array}{c}1-6 \\
1-6 \\
1-6 \\
-\end{array}$ & $\begin{array}{l}\text { Semantic differential } \\
\text { Survey } \\
\text { Semantic differential } \\
\text { Associated words }\end{array}$ & $\begin{array}{c}\text { Unpleasant/Pleasant } \\
\text { Cheap/Expensive } \\
\text { Classic/Modern } \\
\text { Repetition }\end{array}$ \\
\hline
\end{tabular}

The service times of the different proposals have been analyzed according to the number of actions to be carried out and also the distance the user has to travel between them, evaluating both parameters based on the observation and analysis of the different tasks. On the other hand, usability and safety are included in the behavioral level, to analyze the user's behavior towards the vehicle. In this case, usability is segmented into the parameters of intuitiveness, cleanliness, maintenance, and others; while worker safety is studied on the basis of the different anthropometric tables, taking into account the worker's postural control. All the parameters related to usability have been evaluated using the "semantic differential" technique. Safety was been analyzed on the basis of different ergonomics regulations and recommendations in the workplace.

At the visceral level, the user's first impression of the proposals studied was examined. Parameters such as attractiveness, quality and novelty were considered on the basis of data analysis, semantic differential and associated words.

The data obtained facilitate the evaluation and selection of proposals for the optimization of the service in the different dimensions studied and on the basis of specific parameters, transformed into numerical values by the researchers. These two phases are related through the procedures and tools for the dimensioning of the different variables and parameters of interest.

\section{Results}

The different problems encountered in the current service during the early stage are shown below. The evaluation of the selected concepts M1, M5 and M7 mentioned above is also presented here. This evaluation provides companies and researchers with interesting data. With these data, it is possible to design a methodological approach for the development of services tools and machines that require human-machine interaction. 


\subsection{Definition of Current Service Problems}

The problems found after the interviews with the workers of CESPA, Public Company and VERTRESA, Public Company, have been analyzed in the three variables under study: $\mathrm{S}, \mathrm{U}$ and T. Table 5 shows the 16 problems found according to the elements of the vehicle affected (A-P). The classification is composed of the elements "high-pressure water gun", "hose reel", "detergent container", "Control Panel board" and "boiler". The term "vehicle" has also been included for those problems detected throughout the machine.

Table 5. Evaluated parameters.

\begin{tabular}{|c|c|c|c|}
\hline & Security (S) & Service Time $(\mathrm{T})$ & Usability (U) \\
\hline High-pressure water gun & $\begin{array}{l}\text { Overhead use (A) } \\
\text { Supporting in urban elements (B) } \\
\text { Overheating (F) }\end{array}$ & \multicolumn{2}{|c|}{ Complex hold. The user leaves it in the back of the van (D) } \\
\hline Reel hose & $\begin{array}{l}\text { Unsage quick hitch }(\mathrm{G}) \\
\text { Bobbin jam }(\mathrm{O})\end{array}$ & \multicolumn{2}{|l|}{ Automatic lock (I) } \\
\hline \multirow[b]{2}{*}{ Detergent container } & & Complex moorings $(\mathrm{H})$ & \\
\hline & & $\begin{array}{l}\text { Swit off the vehicle to turn off the } \\
\text { water (J) }\end{array}$ & \\
\hline Control panel board & & \multicolumn{2}{|c|}{$\begin{array}{l}\text { Unintuitive on/off }(\mathrm{C}) \\
\text { Very dim lighting }(\mathrm{N})\end{array}$} \\
\hline \multirow{3}{*}{ Vehicle } & \multirow{3}{*}{ Overheating (F) } & \multirow{3}{*}{$\begin{array}{l}\text { Problematic van parking }(\mathrm{M}) \\
\text { Distribution of elements }(\mathrm{P})\end{array}$} & Check interior levels $(\mathrm{K})$ \\
\hline & & & $\begin{array}{c}\text { To leave vehicle without checking } \\
\text { anything }(\mathrm{L})\end{array}$ \\
\hline & & & Height of van (E) \\
\hline Boiler & Alternative to diesel boiler $(\mathrm{Q})$ & & \\
\hline
\end{tabular}

In terms of safety, most of the problems are observed at the "high-pressure water gun" and the "hose reel". This is due to ergonomic and functional reasons. The three current elements can cause injuries and wounds (A, F, G, N and O), but there are also risks in the boiler (N) and in the vehicle itself (F). Pedestrian safety is also compromised, especially by the high-pressure water gun (B). When the worker uses it, he places both arms above his head, detecting unwanted angles and postures that can cause injury (A). In addition, the hose rewind system causes the hose to clog, making the worker's task more difficult and reducing his safety $(\mathrm{O})$. Constant pulling is necessary to ensure full service, and injury to the shoulder area may also occur. The quick coupling of the reel can loosen, causing burns $(G)$, as with overheating of the vehicle (F) and the high-pressure water gun.

The safety of pedestrians and urban furniture is endangered when the worker leaves the high-pressure water gun on objects of the road (B) or simply on the ground. This problem is even greater when hot water is used.

On the other hand, most of the elements present problems in the "service time" and in the performance of the different actions, which implies a high duration of the whole service. The most difficult elements in this respect are the reel hose, the detergent containers, the high-pressure water gun, the control panel board and those derived from the vehicle's own equipment to perform the tasks.

In this sense, it is important to highlight that there are certain elements that transfer the problem of usability to usage times. This occurs because the worker does not perform the action as intended (D) in order to avoid the complexity of the task, which would lengthen the service time of each action. Among these direct human-product interactions, the high service time involved in the safety, locking and fastening systems of the different elements (D, H, I and J) stands out.

In addition, the distribution of the vehicle's components increases the distance the worker has to travel between the actions to be carried out (P, K, L, E). Moreover, as the vehicle is positioned in front of the containers instead of parallel to them, it obstructs the 
passage of private vehicles and pedestrians. It is therefore sometimes necessary to change the van in order to continue with the same service $(\mathrm{M})$.

Among the usability levels, in addition to those mentioned above, which translate into a high service time (D, E, K and L), the aspects related to the control panel board stand out. In this item, the switch for selecting hot or cold water presents the on and off indicators in this order: OFF/ON. This is not intuitive and sometimes leads to confusion when the worker expects to find the option to turn on first and turn off later $(\mathrm{C})$. On the other hand, the intensity of the indicator lights on the control panel board $(\mathrm{O})$ can also be a problem for ease of use. It is button-shaped and, in addition, in environments where the light outside the vehicle is bright, the worker may not be able to distinguish when the indicator is on and when it is off.

\subsection{Evaluation of Alternatives}

Based on these 16 problems detected, the different proposals mentioned above have been developed with and without changes in distribution, analyzing the three alternatives indicated in the previous sections: M1, M5 and M7.

In particular, Table 6 shows the problems solved by the different proposals (in green) and also the number of actions that need to be carried out to implement the full service.

Table 6. Problems solved by different proposals.

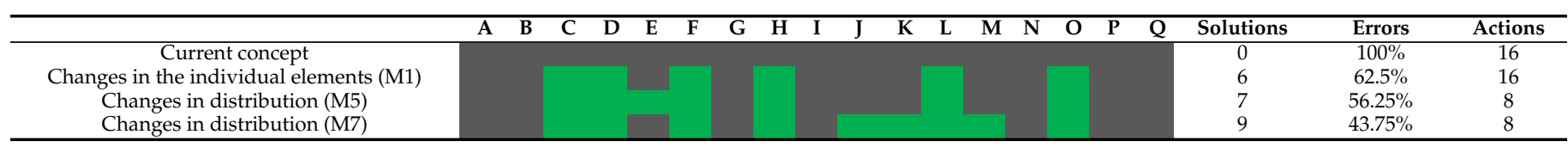

The table compares the current concept, in which a total of 16 problems have been identified $(\mathrm{A}-\mathrm{Q})$ with the combination of individual proposals (which would include proposal M1), and the two full proposals that include changes in distribution (M5 and M7). The combination of individual proposals is done in order to be able to analyze a complete service, although only the control panel board (M1) will be analyzed below.

During this analysis, it can be observed that the combination of individual modifications resolves a total of six errors (C, D, F, H, L and O). This represents a reduction of 37.5\% of the errors, while keeping only $62.5 \%$ of the errors, as well as the same number of actions required for the current service: 16 .

On the other hand, the proposals involving changes in the distribution of the different components (M5 and M7) both show a 50\% reduction, requiring the development of only eight actions. The M5 concept reduces by seven the errors committed in the current concept while maintaining $56.25 \%$ of the errors, and the M7 concept implements a total of nine solutions with only $43.75 \%$ of the errors.

Given the similarity in the number of actions of these two proposals, the comparative service times are analyzed below according to the distance between the different actions to be carried out (Table 7). For these measurements, we have taken into account whether the distance is low (in green), medium (in grey) or high (in black), the optimum value being the "low" distance. As shown in the table, 1, 2 or 3 points have been considered for the measurement, with the lowest value being the most expected.

Table 7. Effectiveness in times of use according to the distance between operations.

\begin{tabular}{|c|c|c|c|c|c|c|c|c|c|c|c|c|c|c|c|}
\hline & 1 & 2 & 3 & 4 & 5 & 6 & 7 & 8 & 9 & $10 \quad 11$ & 12 & 13 & 14 & Weighting & Distance \\
\hline M5 & 1 & 2 & 1 & 3 & 1 & 2 & 2 & 1 & & n environment & 1 & 3 & 3 & 20 points & $100 \%$ \\
\hline M7 & 1 & 2 & 2 & 2 & 1 & 1 & 1 & 1 & & n environment & 1 & 2 & 2 & 16 points & $76.2 \%(-23.8 \%)$ \\
\hline
\end{tabular}

While proposal M5 would score 20 points proposal M7 would only score 16 points. Therefore, it can be stated that the second proposal reduces the distance between operations by $23.8 \%$. 


\subsection{Times of Use, Visceral Level and Behavioral Level of the Proposals}

Following the indications set in the methodology, the data obtained in the analysis of service time, behavioral and visceral level are shown comparatively in Table 8. In the case of proposals M5 and M7 (columns 4 and 5), they are analyzed comparatively with each other. Meanwhile, proposal M1 (column 3) is analyzed separately. This proposal is an individual concept that does not involve the realization of the whole service, and therefore requires comparison with 10 actions out of the 16 total actions of the whole process.

Table 8. Analysis of the different alternatives proposed.

\begin{tabular}{|c|c|c|c|c|c|}
\hline Dimension & & Parameters & M1 & M5 & M7 \\
\hline Service time & Actions & $\begin{array}{c}\text { No. of actions } \\
\text { Distance between actions }\end{array}$ & $\begin{array}{l}7 \text { (from } 10) \\
-30 \%\end{array}$ & $\begin{array}{c}8 \\
100 \%\end{array}$ & $\begin{array}{c}8 \\
-23.8 \%\end{array}$ \\
\hline \multirow{3}{*}{$\begin{array}{l}\text { Behavioral } \\
\text { level }\end{array}$} & \multirow{2}{*}{ Usability } & $\begin{array}{c}\text { Ease of use } \\
\text { Symplicity } \\
\text { Cleaning and maintenance }\end{array}$ & $\begin{array}{c}67 \% \\
76.67 \% \\
-\end{array}$ & $\begin{array}{l}70.65 \% \\
52.71 \% \\
76.14 \%\end{array}$ & $\begin{array}{l}74.80 \% \\
45.15 \% \\
81.23 \%\end{array}$ \\
\hline & & Others & Cleaning & $\begin{array}{l}\text { Agile | Spacious | } \\
\text { Simple | Cash | } \\
\text { Useful }\end{array}$ & $\begin{array}{l}\text { Accessible | Easy | } \\
\text { Practical | Simple | } \\
\text { Comfortable | Usable }\end{array}$ \\
\hline & & Security & - & & \\
\hline \multirow{2}{*}{ Visceral level } & & $\begin{array}{l}\text { Atraction } \\
\text { Quality } \\
\text { Novelty }\end{array}$ & $\begin{array}{c}18.33-32.03 \% \\
- \\
-\end{array}$ & $\begin{array}{l}68.82 \% \\
53.06 \% \\
72.40 \%\end{array}$ & $\begin{array}{l}66.79 \% \\
50.29 \% \\
63.63 \%\end{array}$ \\
\hline & & Other & $\begin{array}{l}\text { Vehicle cleaning | } \\
\text { Hot water cleaning | } \\
\text { Urban cleaning }\end{array}$ & $\begin{array}{c}\text { Caravan | Compact } \\
\text { | Dynamic | } \\
\text { Innovative | New | } \\
\text { Professional }\end{array}$ & $\begin{array}{c}\text { White | Compact | } \\
\text { Scattered | Interesting | } \\
\text { Necessary }\end{array}$ \\
\hline
\end{tabular}

\subsubsection{Proposals with Change in Their Distribution (M5 and M7 Concepts)}

The analysis carried out on "service time" shows an advantage of the proposed M7 concept over M5. Although no differences are found in the first parameter analyzed"number of actions" - there is a reduction in the distance between the different actions, which is $23.8 \%$ less in the M7 proposal than in the M5.

In terms of performance, the parameters of "ease of use" and "cleanliness and maintenance" stand out for the M7 proposal with four and five points, respectively. However, the M5 concept stands out for its simplicity, this time with a seven-point difference over the M7 concept. Therefore, there are no major differences between their interest, although there is a certain preference for the M7 proposal at this level, with a greater number of adjectives of interest in the words associated with this concept on the part of the users consulted.

On the visceral level, and in particular in that first impression of the product, the M5 concept stands out in parameters such as attractiveness, quality and novelty. However, it does so by two and three points on the first two parameters and is rated only eight points higher than the first. Users have also associated words like "new" and "innovative" with the first concept, so the differences in perception between the two proposals do not seem too important, and a negative value ("scattered") has been found for the M7 proposal, while no negative value has been found for M5.

\subsubsection{Control Panel (M1 Concept)}

As can be seen in Table 8, the results indicate a high percentage of users who find the control panel board intuitive. Specifically, $67 \%$ consider it easy to use, and $76.67 \%$ highlight its simplicity.

Interestingly, respondents are hardly influenced by professional background, gender or age when it comes to getting the functions of each button right or wrong. However, during the interaction between each participant and the product, users suggest further improvements. In particular, the users suggest adding color graphics on the board, as well as some explanatory words on the emergency stop, which is not identified by all users. In 
addition, it is proposed to add the symbols "-" and "+" to the graphics associated with water pressure regulation and to change the symbol of the working light to a light bulb.

Among the measurements made on the level of attraction, it is striking that only $18.33 \%$ of the users consulted were attracted to the proposal, and these users were inexperienced in this type of work environment. However, when asked about the attractiveness of this proposal for experienced users, the level rose to over $30 \%$.

Finally, the associations that users have made with this product have also been interesting, relating it to cleaning elements, especially vehicles, hot water and urban cleaning.

\section{Conclusions}

Nowadays, it is clear that industrial design is fundamental to the exercise of innovation in companies. The creation of everyday products capable of meeting user needs is essential to keep business and environment competitive.

There are several techniques, methodologies and tools to measure, validate and adapt the product to the user. These tools are capable of devising successful and desired products by the market, which generate a growing offer, where the user has a very high power imposed on the characteristics of the products. For this reason, product evaluations are essential in the early design phase to ensure the correct acceptance of each product by the target user.

However, despite these data, the labor market and workers have less decision-making power and demand in the face of a much lower supply of products, tools and machines than generic products. Added to this is the need to economize on processes and tools in order to increase company profits, often while maintaining the safety and well-being of the workers themselves.

There is a wide body of research that examines the working environments. Some develop measures of company or service productivity, and others focus on worker wellbeing. However, the existence of various hazards in different workplaces makes it difficult to assed both, productivity and worker well-being.

There are several methodologies and tools for assessing ergonomics at work. The approach that provides the best results is observation, through which more innovative methodologies (which include the use of new technologies) or more traditional ones (which are simpler and cheaper to apply) are distributed. Despite this, they are not usually included in the design process. They also do not analyze the human-machine interaction, but rather the user's position with the static elements. In most cases, these are office elements or work tools. Therefore, this research can be considered as a starting point for the development of a methodology to assess the quality of a workstation that requires human-machine interaction and the resulting service.

This approach not only assists in the evaluation of working environments but also seeks service optimization through the evaluation of proposals during the early stages of the design process. Although the approach was observational and the tools were traditional, the use of augmented reality in successive phases of the design process can be interesting. With this technology, it would be possible to evaluate complete designed (not yet manufactured) solutions, and both the design of the elements and the layout of the existing ones.

After the development of the case study, the results show the possibility of predicting the evolution of the different alternatives designed in terms of service time, safety and usability. The results show that the variables are directly related and that productivity, ergonomics and worker well-being and the company's profits are closely related. It is therefore necessary to develop products and test new proposals according to each of the variables.

At the same time, the aim is to seek the profitability of the services provided by the companies to society, under the study of the three factors, showing in the three cases a series of important deficiencies not previously raised in a specific case: a washing vehicle for urban cleaning. 
Gaps have been identified from two methodologies used in the conventional product design: UCD and emotional design. These methodologies have been perfectly adapted to the case study, so it can be affirmed that their application is favorable to the design of products for professional practice. With the application of these methodologies, it has been possible to demonstrate through qualitative and quantitative results the effectiveness of these methodologies in the evaluation and testing of products for professional practice.

Specifically, 16 errors have been detected pertaining to five vehicle components, as well as to the vehicle as a whole. Most of them are related to service time, and it is observed that improving them increases the usability of the machine and the safety of the worker. Thus, the data provided by the study are essential to increase the competitiveness of a company, but also the well-being of the worker. This competitiveness increases service improvement (users) and worker safety.

Furthermore, from the analysis of these errors, it has been possible to reduce the complete service time by $50 \%$, allowing the use of tools intended for the use of conventional products, and visceral and behavioral levels of design.

The study also shows that it is possible to improve the intuitiveness of a professional product by consulting inexperienced users.

On the other hand, it is noted that the modification of individual elements is less productive than the modification of the layout of the different elements that make up the vehicle. Comparatively, it is observed that modifications of individual elements (except for those made on the vehicle's control panel board) suggest a lower level of optimization than modifications of the layout, which makes it important to test and develop the usual observational tests in the UCD, which also have a very low or even zero-cost, including both experienced and inexperienced users of this service. In proposal M1 (which obtains the best results among the individual concepts) the service is simplified by just over $37 \%$, accumulating $62.5 \%$ of the errors of the initial proposal and the same number of tasks to be developed in each service (16). Proposals that include changes in the distribution of elements and actions reduce errors by more than $56 \%$, and the number of actions by $50 \%$.

This fact highlights, once again, the need to take into account human-machine interactions in the design of machines and tools that assist the operator in the development of services. In turn, this establishes the need to generate methodologies for the evaluation and design of machines and tools used by different operators.

The developed case study invites the development of new methods of measurement and product design focused on work and service development, as well as the collaboration of research teams and companies to increase the competitiveness of business and improve business services and the quality of work of the working users.

Author Contributions: Conceptualization, M.A.-G., P.J.-M., M.F.-R. and A.G.-S.; methodology, M.A.G.; software, P.J.-M. and A.G.-S.; validation, M.F.-R., P.J.-M. and A.G.-S.; formal analysis, M.A.-G.; investigation, P.J.-M. and A.G.-S.; resources, M.F.-R.; data curation, P.J.-M., and A.G.-S.; writingoriginal draft preparation, M.A.-G. writing—review and editing, M.A.-G.; visualization, M.F.-R.; supervision, M.A.-G. and M.F.-R.; project administration, M.A.-G. and M.F.-R.; funding acquisition, M.A.-G. and M.F.-R. All authors have read and agreed to the published version of the manuscript.

Funding: This research was funded by University of Cádiz.

Informed Consent Statement: Informed consent was obtained from all subjects involved in the study.

Conflicts of Interest: The authors declare no conflict of interest.

\section{References}

1. Muhammad, M.K.; Shahriman, A. Unconscious Human Behavior at Visceral Level of Emotional Design. Procedia-Soc. Behav. Sci. 2013, 105, 149-161.

2. World Design Organization. Available online: https://wdo.org/ (accessed on 1 May 2020).

3. Van Kleef, E.; van Trijp, H.C.M.; Luning, P. Consumer research in the early stages of new product development: A critical review of methods and techniques. Food Qual. Prefer. 2005, 16, 181-201. [CrossRef] 
4. Roy, R.; Goatman, M.; Khangura, K. User-centric design and Kansei Engineering. CRIP J. Manuf. Sci. Technol. 2008, 1, 172-178. [CrossRef]

5. Aftab, M.; Rusli, H.A. Designing Visceral, Behavioural and Reflective Products. Chin. J. Mech. Eng. 2017, 30, 1058-1068. [CrossRef]

6. Rusli, H.A.; Aftab, M. Unbroken: Rediscovering long-term value of products through change in perception. In Proceedings of the International Workshop on Digital Design and Manufacturing Technologies-Embracing Industry 4.0 and Beyond, Newcastle Upon Tyne, North East England, UK, 12-13 April 2016.

7. Forlizzi, J.; Ford, S. The building blocks of experience: An early framework for interaction designers. In Proceedings of the 3rd conference on Designing Interactive Systems: Processes, Practices, Methods, and Techniques, New York, NY, USA, 17-19 August 2000; pp. 419-423.

8. Almeida Torres, A.R.; Osawa Chagas, M.I.; Araújo Moreira, A.C.; de Holanda Cunha, I.C.; Rodrigues, E.M. O adoecimento no trabalho: Repercussões na vida do trabalhador e de sua familia. Sanare—Rev. Políticas Públicas 2011, 10, 42-48.

9. Raja Shere, M.S.; Bavithra, B. An exploration on occupational hazards towards healthcare workers. J. Contemp. 2021, 26, 189-195. [CrossRef]

10. Smallwood, J.; Deacon, C. Occupational Health $(\mathrm{OH})$ Practices in South African Construction. MATEC Web Conf. 2020, $312,03003$. [CrossRef]

11. Morrison, R.L.; Smollan, R.K. Open plan office space? If you're going to do it, do it right: A fourteen-month longitudinal case study. Appl. Ergon. 2020, 82, 102933. [CrossRef]

12. Almeida, T.E.N.; Ferreira, R.E.D.A.; Bezerra, L.N.; Pereira, T.M.D.M. Analysis of the prevalence of musculoskeletal disorders and occupational stress in professors of a higher education institution in the state of Pernambuco. Rev. Bras. Med. Trab. 2020, 18, 274-279. [CrossRef]

13. Castillo-Martinez, A.; Medina-Merodio, J.A.; Gutierrez-Martinez, J.M.; Aguado-Delgado, J.; de-Pablos-Heredero, C.; Otón, S. Evaluation and Improvement of Lighting Efficiency in Working Spaces. Sustainability 2018, 10, 1110. [CrossRef]

14. NIOSH. Observation-Based Posture Assessment: Review of Current Practice and Recommendations for Improvement; National Institute for Occupational Safety and Health: Cincinnati, OH, USA, 2014.

15. McAtamney, E.L.; Corlett, N. RULA: A survey method for the investigation of work-related upper limb disorders. Appl. Ergon. 1993, 24, 91-99. [CrossRef]

16. Hignett, S.; McAtamney, L. Rapid entire body assessment (REBA). Appl. Ergon. 2000, 31, 201-205. [CrossRef]

17. Sonne, M.; Villalta, D.L.; Andrews, D.M. Development and evaluation of an office ergonomic risk checklist: ROSA-Rapid office strain assessment. Appl Ergon. 2012, 43, 98-108. [CrossRef]

18. David, G.C. Ergonomic methods for assessing exposure to risk factors for work-related musculoskeletal disorders. Occup. Med. 2005, 55, 190-199. [CrossRef] [PubMed]

19. Gašo, M.; Krajčovič, M.; Dulina, L’.; Grznár, P.; Vaculík, J. Methodology of Creating and Sustainable Applying of Stereoscopic Recording in the Industrial Engineering Sector. Sustainability 2019, 11, 2194. [CrossRef]

20. Marogel-Popa, T.; Marcu, M.V.; Borz, S.A. Postural Risk in Manual Planting Operations of Poplar: Two Options Compared. Sustainability 2020, 12, 5531. [CrossRef]

21. Robert, F.; Yili, L.; Don, C.; Glenn, J.; Brad, J. Computer-aided ergonomics: A case study of incorporating ergonomics analyses into workplace design. Appl. Ergon. 2000, 31, 291-300. [CrossRef]

22. Gašová, M.; Gašo, M.; Štefánik, A. Advanced Industrial Tools of Ergonomics Based on Industry 4.0 Concept. Procedia Eng. 2017, 192, 219-224. [CrossRef]

23. Matos, M.; Arezes, P.M. Ergonomic Evaluation of Office Workplaces with Rapid Office Strain Assessment (ROSA). Procedia Manuf. 2015, 3, 4689-4694. [CrossRef]

24. Desmet, P.M.A. Faces of Product Pleasure: 25 Positive Emotions in Human-Product Interactions. Available online: https: / / diopd.org/wp-content/uploads/2012/09/faces-of-product-pleasure-published.pdf (accessed on 6 January 2021).

25. Desmet, P.M.A.; Ortíz Nicolás, J.C.; Schoormans, J.P. Product personality in physical interaction. Des. Stud. 2008, 29, 458-477. [CrossRef]

26. Demir, E.; Desmet, P.M.A.; Hekkert, P. Appraisal Patterns of Emotions in Human-Product Interaction. Int. J. Des. 2009, 3, 41-51.

27. Alonso-García, M.; Pardo-Vicente, M.-Á.; Rodríguez-Parada, L.; Moreno Nieto, D. Do products respond to user desires? A case study. Errors and successes in the design process, under the umbrella of emotional design. Symmetry 2020, 12, 1350. [CrossRef]

28. Becattini, N.; Borgianni, Y.; Cascini, G.; Rotini, F. Investigating users' reactions to surprising products. Des. Stud. 2020, $69,100946$. [CrossRef]

29. Norman, D.A. The Design of Everyday Things; Basic Books: New York, NY, USA, 1988.

30. Norman, D.A. Emotional Design; Basic Books: New York, NY, USA, 2004.

31. Norman, D.A. Emotional Design: Why We Love or Hate Everyday Things; Hachette: London, UK, 2007.

32. Veryzer, R.W.; De Mozota, B.B. The Impact of User-Oriented Design on New Product Development: An Examination of Fundamental Relationships. J. Prod. Innov. Manag. 2005, 22, 128-143. [CrossRef]

33. Abras, C.; Maloney-Krichmar, D.; Preece, J. User-Centered Design. In Encyclopedia of Human-Computer Interaction; Bainbridge, W., Ed.; Sage Publications: Thousand Oaks, CA, USA, 2004

34. van Boeijen, A.; Daalhuizen, J.; Zijlstra, J.; van der Schoor, R. Delft Design Guide: Design Methods; BIS Publishers: Amsterdam, The Netherlands, 2014. 
35. Goulding, C. Grounded Theory, Ethnography and Phenomenology Strategies for Marketing Research. Eur. J. Mareting 2005, 39, 294-308. [CrossRef]

36. Bruseberg, A.; Mcdonagh-Philp, D. Focus Groups to Support the Industrial/Product Designer: A Review Based on Current Literature and Designers' Feedback. Appl. Ergon. 2002, 33, 27-38. [CrossRef]

37. Doi, T. Value-centered design process for user experience enhancement: A case study in the development of a notebook PC. Ergon. Des. Mag. Hum. Factors Appl. 2020. [CrossRef] 